methylphenidate (Science 1977; 198:1274); cognitive performance was maximized at a dosage of $0.3 \overline{\mathrm{mg}} / \mathrm{kg}$ and was impaired by dosages of $1.0 \mathrm{mg} / \mathrm{kg}$ or higher. The present study indicated that the larger dosage resulted in a leveling of academic performance and not a decline. The authors admit that the high dose may have enabled the children to sit still and be quiet thereby facilitating their cognitive functioning. In attempting to determine an optimal dose for each child it is essential that the physician notes the dose response and timed course of action on academic, cognitive, and behavioral performance.

\title{
RATING SCALES IN ATTENTION DEFICIT DISORDER
}

A comparison of parent, teacher, and child performance rating scales in the diagnosis and follow-up of methylphenidate treated children with $\mathrm{ADDH}$ is reported from Developmental Pediatrics, San Antonio, TX; Department of Pediatrics, Madigan Army Medical Center, Tacoma, WA; and Department of Pediatrics, William Beaumont Arny Medical Cener, El Paso, TX. The three clinical tools provided varying degrees of supportive data during diagnosis and treatment of 21 children with $A D D / H$. The ADD-H Comprehensive Teacher Rating Scale classified $67 \%$ as having $\mathrm{ADD} / \mathrm{H}$ and $14 \%$ as borderline. The Conners' Parent Rating Scale-Revised identified $71 \%$ as having $\mathrm{ADD} / \mathrm{H}$. The Gordon Diagnostic System showed $52 \%$ as having $\mathrm{ADD} / \mathrm{H}$ and 298 as borderline. During treatment with methylphenidate, the teacher rating scale showed an increase in attention span and a decrease in hyperactivity, the parent rating scale showed a significant decrease in hyperactive behavior and the Gordon child performance scale showed no significant change. (Cohen $\mathrm{ML}$ et al. Parent, Teacher, Child: A trilateral approach to attention deficit disorder. AJDC October 1989; $143: 1229-1233$ ).

COMMENT. The teacher and parent rating scales were helpful in monitoring the effects of treatment with methylphenidate while the child performance-dependent test was insensitive to drug effects.

\section{SOHDOL BREAKFAST PROGRAM AND SCHDOL PERFORMANCE}

The effects of participation in the school breakfast program by low incame children on academic achievement and rates of absence and tardiness are reported from the Department of Pediatrics, Boston City Hospital, Boston, MA. The results in children grades 3-6 in the Lawrence, Mass, public schools were compared with those children who also qualified but did not participate in the breakfast program. Participation in the program had a significant association with improvement in standardized achievement test scores and the rates of absence and tardiness. (Meyers AF et al. School breakfast program and school performance. AJDC Oct $1989 ; 143: 1234-1239$ ).

COMMENT. Further study of this question is indicated, using prospective control designs as well as data regarding protein, fat and carbohydrate content of the meals. Conners has reported beneficial effects on behavior and learning of a sugar load following a protein breakfast whereas adverse effects were noted with sugar alone. (Personal cammication). 